\title{
Metabolism of Benzene in Nonfasted, Fasted, and Aryl-Hydroxylase Inhibited Rats ${ }^{1}$
}

\author{
Herbert H. Cornish and Richard C. Ryan \\ Department of Industrial Health, School of Public Health, Institute of Industrial Health, \\ University of Michigan, Ann Arbor, Michigan 48104 \\ Received June 26, 1964
}

The metabolism of benzene has been intensively studied, and its metabolic fate in the rabbit is well documented (Williams, 1959). Although partially excreted in the expired air, 30-40\% of ingested or inhaled benzene is hydroxylated and excreted as various phenolic products. These may appear in the urine in free or conjugated form.

Recent studies of the enzymatic hydroxylating mechanism in liver indicate that this enzyme system is present in the microsomal fraction of liver cells (Mitoma $e t a l$., 1956) and requires TPNH and oxygen for activity. It appears that the hydroxylating enzyme system is also responsible for a number of other metabolic processes, including $\mathrm{N}$-demethylation. A report by Roth and Bukovsky (1961) indicates that the N-demethylating enzyme activity of rabbit liver drops almost to zero after 24 hours of fasting. If hydroxylating activity is also depressed to this extent by fasting, then the immediate nutritional state of animals during toxicity testing procedures may play a most important role in determining the degree of toxicity which becomes apparent during the test period. One can foresee that aromatic compounds which are hydroxylated to produce metabolites more toxic than the parent compound would have an apparent decreased toxicity in animals unable to hydroxylate the ingested compound. Conversely, compounds hydroxylated to yield metabolites which are less toxic than the parent compound would appear more toxic in animals with impaired hydroxylating mechanisms. Thus fasting, or the presence of chemical compounds that inhibit hydroxylation, may alter the apparent toxicity of ingested chemicals. $\beta$-Diethylaminoethyldiphenylpropylacetate hydrochloride ${ }^{2}(\beta-D D H)$ is a compound which has been shown to inhibit the hydroxylating enzyme system (Cook et al., 1954).

The present study was designed to determine the effect of fasting and the injection of $\beta$-DDH on the acute oral toxicity and metabolic fate of benzene.

\section{METHODS}

Acute oral toxicity. Male Sprague-Dawley rats of the Holtzman strain, weighing 200-250 g, were utilized in the acute toxicity tests. Oral toxicity was determined by feeding geometrically graded dosages of reagent-grade benzene ${ }^{3}$ to groups of 10 rats at each dosage. The $\mathrm{LD}_{50}$ and $95 \%$ confidence level were calculated by the method

1 This study was supported, in part, by U.S. Public Health Service research grant no. MH03692 from the Institute of Mental Health, National Institutes of Health.

2 SKF 525-A, Smith, Kline \& French Laboratories, Philadelphia, Pennsylvania.

3 Mallinckrodt Chemical Works, St. Louis, Missouri. 
of Weil (1952). The $\mathrm{LD}_{50}$ 's of benzene were determined for rats on the following treatments: (a) nonfasted; (b) fasted for 24 hours; (c) nonfasted, but injected with $80 \mathrm{mg} / \mathrm{kg}$ of $\beta-\mathrm{DDH}$ intraperitoneally 45 minutes prior to oral administration of benzene; and (d) fasted for 24 hours and injected with $80 \mathrm{mg} / \mathrm{kg}$ of $\beta-\mathrm{DDH} 45$ minutes prior to oral administration of benzene.

Metabolism. Male rats similar to those uscd in the acute toxicity tests, weighing 200-250 g, were maintained on a normal test $\operatorname{diet}^{4}$ and in individual metabolism cages designed for the collection of urine uncontaminated by food or feces. Complete urine samples were collected by a gentle squeezing of each animal at the end of the 24-hour period. The samples were diluted to $20 \mathrm{ml}$ with water, mixed, filtered, and utilized for the determination of phenols and glucuronides. The Dische (1947) method was used for the determination of glucuronides. Standard solutions were prepared from recrystallized D-glucuronic acid. ${ }^{5}$ Free and total phenols were measured with the Folin-Ciocalteu (1927) reagent standardized against pure phenol. Conjugated phenols were calculated as the difference between total and free phenols. Individual 24-hour urine samples were collected daily on all rats for a control period of 4 days, prior to the treatments described below.

One group of 8 rats was injected intraperitoneally with $88 \mathrm{mg}$ of benzene, and 24-hour urine samples were collected daily for the next 4 days. Another group of 8 rats was fasted for 48 hours. Four animals of this group received $88 \mathrm{mg}$ of benzene intraperitoneally after the first 24 hours; the others were maintained as controls. The 24-hour period of urine collection commenced with the benzene injection. The third group of 8 animals was injected intraperitoneally with $80 \mathrm{mg} / \mathrm{kg}$ of $\beta-\mathrm{DDH}$; 45 minutes later, 4 of these animals received a single $88-\mathrm{mg}$ intraperitoneal dose of benzene. Twenty-four-hour urine samples were collected over the subsequent 4 days.

\section{Acute Oral Toxicity}

RESULTS

The $L D_{50}$ of benzene for nonfasted rats was found to be $0.93(0.71-1.23) \mathrm{g}$ of benzene per kilogram. In 24-hour fasted rats, the $\mathrm{LD}_{50}$ was $0.81(0.69-0.95) \mathrm{g} / \mathrm{kg}$. The $\mathrm{LD}_{50}$ in $\beta$-DDH-treated rats was $1.04(0.69-1.57) \mathrm{g} / \mathrm{kg}$; and in 24-hour fasted $\beta$-DDH-treated rats, $0.76(0.51-1.01) \mathrm{g} / \mathrm{kg}$. At high dosages of benzene $(1.87 \mathrm{~g} / \mathrm{kg})$ the animals developed tremors and tonic-clonic convulsions, and many died within 20 minutes. A single dose of $88 \mathrm{mg}$ produced slight central nervous system depression, but no deaths. Hence, this amount was used in subsequent metabolic studies.

\section{Metabolism}

In Fig. 1 are shown the daily excretions of glucuronide and free and total phenol. Normal free phenol excretion in any one group of rats (days 1-4) varies by not more than $2 \mathrm{mg}$ in 24 hours. The injection of benzene on day 4 into nonfasted or 24-hour fasted rats resulted in marked increases $(P<0.001)$ in free phenol excretion during the subsequent 24-hour period (Fig. 1B). Within 48 hours, these values are again within the normal range. Fasting alone results in a slight decrease $(P<0.001)$ in free phenol excretion. The injection of $\beta$-DDH prior to benzene injection (Fig. 1E)

4 Nutritional Biochemicals Corporation, Chagrin Falls, Ohio.

5 Sigma Chemical Company, St. Louis, Missouri. 
results in a marked depression $(P<0.001)$ of the expected free phenol excretion, but not a complete block. $\beta$-DDH does not markedly alter free phenol excretion in control rats.

The data with respect to total phenol excretion are more variable from day to day but several comments are appropriate. After benzene injection (day 4), total phenols
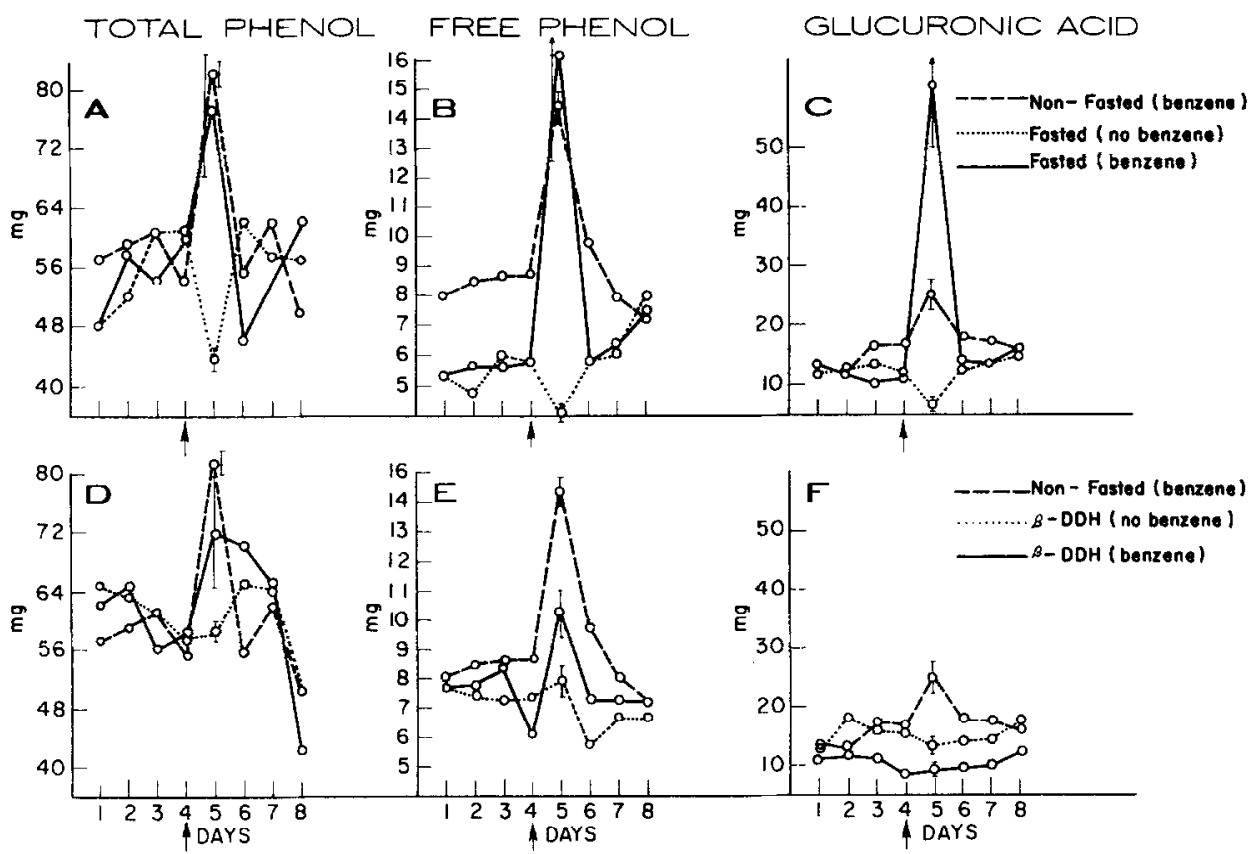

FIG. 1. Daily excretion of metabolites in nonfasted, fasted, and $\beta$-DDH-treated rats. The first 4 days are control days. The vertical bars represent the standard error of the mean excretion for day 5. Where the administration of benzene is indicated, the animals received an intraperitoneal injection of $88 \mathrm{mg}$ of benzene at the end of day 4 as indicated by the arrow. $\beta-\mathrm{DDH}, 80 \mathrm{mg} / \mathrm{kg}$ intraperitoneally, was also administered at this time (45 minutes prior to the dose of benzenc when the two were given to the same animal).

are markedly elevated $(P<0.001)$ above control levels (Fig. 1A). This represents an increase of approximately $25 \mathrm{mg}$ of conjugated phenol per 24 hours, including both glucuronide and other conjugated phenols. $\beta$-DDH injection prolongs total phenol excretion over a period of several days following benzene injection (Fig. 1D). In benzene-injected, fasted rats, total phenol excretion is nearly double that of benzene-injected, nonfasted rats if one considers the low total phenol excretion in fasted animals (Fig. 1A).

The data with respect to glucuronide excretion are quite clear (Fig. 1C,F). The injection of benzene results in a small increase in glucuronide excretion during the subsequent 24-hour period $(P<0.001)$. Fasted animals show a slight reduction in glucuronide excretion $(P<0.001)$, but fasted animals injected with benzene exhibit an increase in glucuronide excretion which is approximately three times the increase noted in nonfasted benzene-injected rats. The administration of $\beta-\mathrm{DDH}$ inhibits the excretion of benzene as the glucuronide (Fig. 1F). 
Total excretion of injected benzene is shown in Table 1. In this table, excretion of the various metabolites is expressed as milligrams of injected benzene and is calculated over the 24-hour period following the injection of benzene, except in the case of total phenol excretion after $\beta-\mathrm{DDH}$ treatment, where a significant excretion during the second 24-hour period is included in the total. In nonfasted animals injected with

TABLE 1

Mean Urinary Excretion of Benzene Metabolites in Nonfasted, Fasted, and $\beta$-DDH-Treated Rats Receiving 88 Mg OF Benzene Intraperitoneally

\begin{tabular}{lcccc}
\hline \multicolumn{1}{c}{ Group ${ }^{a}$} & $\begin{array}{c}\text { Glucuronide } \\
(\mathrm{mg})^{b}\end{array}$ & $\begin{array}{c}\text { Free phenol } \\
(\mathrm{mg})^{h}\end{array}$ & $\begin{array}{c}\text { Conjugated } \\
\text { phenol (mg })^{h}\end{array}$ & $\begin{array}{c}\text { Total } \\
\text { excretion } \\
(\%)\end{array}$ \\
\hline Nonfasted & 4 & 3 & 17 & 23 \\
Fasted 24 hours & $(3-4)$ & $(2-3)$ & $(14-19)$ & 36 \\
B-DDH-treated & 20 & 9 & 23 & 16 \\
(80 mg/kg, i.p. & $(18-21)$ & $(8-10)$ & $(19-25)$ & 12 \\
\hline
\end{tabular}

a Each group contained 8 animals.

$b$ All values are expressed as milligrams of benzene. The range is in parentheses.

c As percentage of the dose.

$88 \mathrm{mg}$ of benzene, only a few milligrams are excreted as free phenol and as glucuronides. The major metabolites are conjugated phenols other than glucuronides. These conjugated phenols account for $14-19 \%$ of the $88 \mathrm{mg}$ dose of benzene given to nonfasted rats. Total excretion of metabolites accounts for approximately $36 \%$ of the dose when $88 \mathrm{mg}$ of benzene is injected into 24-hour fasted rats. $\beta$-DDH prevents the excretion of benzene as the glucuronide, and only a trace of free phenols and approximately $12 \mathrm{mg}$ of benzene as conjugated phenols are excreted over the subsequent 48-hour period.

\section{DISCUSSION}

The excretory pattern of benzene in the normal rat is consistent with that reported for the rabbit (Williams, 1959). The major metabolites in the rat are conjugated phenols, other than glucuronides. In the rabbit, these conjugated phenols are primarily ethereal sulfates. Rats fasted for 24 hours prior to the injection of benzene present an entirely different metabolic picture. There is no increase in conjugated phenol excretion other than that due to a marked increase in glucuronide excretion. This is apparently due to a lack of dietary sulfate and the consequent necessity of metabolizing benzene by alternate pathways. Free phenol excretion is also increased in fasted, benzene-treated rats. Such drastic alterations in metabolic pattern could well result in marked differences in acute toxicity under conditions where metabolic products may differ from the ingested compound in their toxic effects. In the present study, the $\mathrm{LD}_{50}$ 's of benzene were not markedly different in control, fasted, $\beta-\mathrm{DDH}$ injected, and fasted rats injected with $\beta$-DDH in spite of the metabolic differences presented. The prior injection of $\beta$-DDH into rats receiving an intraperitoneal injection of $88 \mathrm{mg}$ of benzene markedly depressed the conversion of benzene to glucuronides and free phenols. Although metabolic patterns were altered in these studies, the total excretory rate of benzene by these routes was perhaps not altered sufficiently 
to affect acute toxicity. Since benzene is also excreted in the expired air, this alternate pathway of excretion may compensate for variations in metabolic fate of volatile substances.

\section{SUMMARY}

The metabolic fate of benzene is markedly altered in rats fasted 24 hours prior to administration of the compouncl. In the nonfasted rat, the major metabolites are conjugated phenols other than glucuronides, while in the fasted rat the major excretory pathway is glucuronide conjugation. In rats treated with $\beta$-diethylaminoethyldiphenylpropylacetate hydrochloride all excretory pathways requiring hydroxylation are depressed. Thus the nutritional state of the animal, as well as prior administration of biologically active compounds, may markedly alter the metabolic fate of ingested compounds and should be considered during metabolic studies or toxicity testing procedures.

\section{REFERENCES}

COoK, L., TONer, J. J., and Fetlows, E. J. (1954). The effect of $\beta$-diethylaminoethyldiphenylpropylacetate hydrochloride (SKF No. 525-A) on hexobarbital. J. Pharmacol. Exptl. Therap. 111, 131-141.

Dische, Z. (1947). A new specific color reaction of hexuronic acids. J. Biol. Chem. 167, 189-198. Folis, O., and Ciocalted, V. (1927). Tyrosine and tryptophan determinations in proteins. J. Biol. Chem. 73, 627-650.

Mitoma, C., Posner, H. S., Reitz, H. C., and Udenfriend, S. (1956). Enzymic hydroxylation of aromatic compounds. Arch. Biochem. Biophys. 61, 431-441.

Roth, J. S., and Bukovsky, J. (1961). Studies on an N-demethylating system in rat liver microsomes. J. Pharmacol. Exptl. Therap. 131, 275-281.

WEIL, C. S. (1952). Tables for convenient calculation of median-effective dose $\left(\mathrm{LD}_{50}\right.$ or $\left.\mathrm{ED}_{50}\right)$ and instructions in their use. Biometrics 8, 249-263.

Williams, R. T. (1959). Detoxication Mechanisms, 2nd ed., pp. 188-194. Wiley, New York. 